\title{
A Survey of Psychological Symptoms One Month Post Discharge in Patients Infected with COVID 19
}

\author{
Ajay Kumar Joopaka ${ }^{1}$, Molanguri Umashankar², Pingali Srilakshmi³, Pradeep SharmaTelkapalli, \\ Chinni Krishna Banoth ${ }^{5}$, N.M. Laxmi Achyutha6, Sailakshmi Kante ${ }^{7}$
}

1, 2, 3, 4, 5, 6, 7 Department of Psychiatry, Gandhi Medical College and Hospital, Secunderabad, Telangana, India.

\section{ABSTRACT}

\section{BACKGROUND}

Corona virus disease or the (COVID 19) has caused mental health problems in the general population, in people infected and hospitalised for the disease and in patients who have recovered from the disease physically but continue to suffer from lingering mental health problems. Studies have shown stress, depression, and anxiety in one third of the survivors. Similarly post-traumatic stress disorder has been reported to be around $13 \%$ in the survivors of COVID 19. In this study, we wanted to assess the psychological symptoms in the survivors of Covid 19 patients, one month post discharge and also assess various factors associated with the same.

\section{METHODS}

A cross sectional telephonic survey of the patients one month following discharge was done to understand the psychological problems. Sociodemographic data was recorded on a semi structured proforma, whereas psychological distress was recorded on patient health questionnaire - 4 (PHQ - 4) and the post-traumatic stress disorder (PTSD) was screened for by the impact of event scale revised (IES - R).

\section{RESULTS}

Of the 200 patients evaluated, $46.8 \%$ scored above 20 on the impact of event scale which was considered to be a positive screen for post-traumatic stress disorder. Moderate psychological distress was reported by $10.5 \%$ and severe by $7.5 \%$ as measured by PHQ - 4. Being married, having other family members effected by the infection and deaths in the family were some of the factors that were significantly associated with psychological distress and symptoms of post-traumatic stress disorder.

\section{CONCLUSIONS}

Continued mental health support needs to be extended to members who are considered to have recovered and discharged from the hospital following the COVID 19 infection.

\section{KEY WORDS}

COVID 19, Psychological Symptoms, Post-Traumatic Stress Disorder
Corresponding Author: Dr Molanguri Umashankar, Professor, Department of Psychiatry, Gandhi Medical College and Hospital, Secunderabad, Telangana, India. E-mail: drajaykmc@gmail.com

DOI: $10.14260 /$ jemds/2021/588

How to Cite This Article: Joopaka AJ, Umashankar M, Srilakshmi P, et al. A survey of psychological symptoms one month post discharge in patients infected with COVID 19. J Evolution Med Dent Sci 2021;10(34):2884-2887, DOI: $10.14260 /$ jemds $/ 2021 / 588$

Submission 08-05-2021,

Peer Review 26-06-2021,

Acceptance 30-06-2021,

Published 23-08-2021.

Copyright (C) 2021 Ajay Kumar Joopaka et al. This is an open access article distributed under Creative Commons Attribution License [Attribution 4.0 International (CC $B Y 4.0)]$ 


\section{BACKGROUND}

COVID - 19 or the corona virus pandemic started in December 2019, like a viral outbreak in Wuhan city of central Hubei province of China. ${ }^{1}$ The first case was reported in India on 30 January and has spread across cities since then. ${ }^{2}$ All those who tested positive during the initial stages of the pandemic were hospitalised to prevent community spread and in them the physical symptoms ranged from mild to severe, sometimes requiring intensive care. They also reported numerous mental health problems, mainly due to the separation from loved ones during the period of hospitalisation, uncertainty of the disease progression, a number of family members being infected and sudden deaths in the family due to the infection. 3,4 Studies in survivors of the previous pandemic have shown that the psychological problems persist even after discharge from the hospital. Studies done in survivors of the severe acute respiratory syndrome (SARS) epidemic in 2014 have revealed that about $35 \%$ of respondents reported moderate to severe anxiety and/or depressive symptoms. It was found that those working as healthcare workers or having family members killed by SARS were more prone to develop subsequent high levels of distress. ${ }^{5}$

Studies done in the current COVID 19 pandemic in China has showed the psychological distress among COVID-19 survivors during early convalescence as $31.0 \%, 22.2 \%$, and $38.1 \%$ of stress, anxiety, and depression respectively. Belonging to the age group of above 60 years and having good social support were protective factors, whereas having post COVID physical discomfort and having other family members infected with COVID 19 added to the stress levels. ${ }^{6}$ Other factors studied in patients living in home isolation due to government restrictions found that being male and having high levels of positive mental well-being were protective factors whereas emotional loneliness and the experience of adverse life events were risk factors. Social loneliness was positively associated with stable mental health, stressing the importance of meaningful relationships. ${ }^{7}$

This aspect of social connectedness was severely strained due to being hospitalised alone without caregivers. A study done specifically on post-traumatic stress disorder in Chinese population found the prevalence to be $13 \%$ following one month of the onset of the pandemic. ${ }^{8}$ PTSD is a stress-related disorder with subsequent autoimmune disease that may arise after exposure to a serious traumatic event or injury, in this case the hospitalisation with the COVID 19 infection.

The acute stress response in patients following a traumatic event may reflect an enhancement of the immune response while chronic stress may reflect a suppression of the immune response with increased susceptibility to infections, that worsens the case of infection with COVID 19.9

Hence the need to identify and treat PTSD is not only needed for regaining optimal mental health but also is needed to reduce further worsening of the infection. During the time of conducting our study there were no studies from India focusing on the psychological distress of the COVID 19 survivors, especially those who were admitted and discharged from the hospital after recovery.
In order to address this lacuna, we intended to study the psychological symptoms in the survivors of Covid 19 patients, one month after discharge.

\section{METHODS}

The study is a cross-sectional telephonic survey of patients one month post discharge from the hospital, after having been hospitalised for COVID 19 from October 2020 to September 2020. Informed consent was taken from all participants at the time of discharge for an interview via a telephone call one month post discharge to enquire about mental health status for the purpose of the study. All those willing to give informed consent and above 18 years of age were called one month later.

Taking $13 \%$ as the proportion ${ }^{8}$ with $95 \%$ confidence interval and $5 \%$ precision, we used the Cochrane formula to calculate the sample size to be 174 . It was rounded off to 200 for the ease of calculation. Convenience sampling technique was used. The total time taken for the telephonic interview ranged from 10 to 15 minutes.

The participants were administered with the following scales.

1. Semi-structured proforma for sociodemographic and illness related factors.

2. The patient health questionnaire-4 (PHQ 4) an ultra-brief screening for anxiety and depression was used to screen for psychological distress. ${ }^{10}$ PHQ- 4 has a total of 4 questions, with the first two being taken from the generalized anxiety disorder scale (GAD 7),11 and the next two from the patient health questionnaire-9 (PHQ-9)12 PHQ-4 total scores range from 0 to 12 , with categories of psychological distress being: none $-0-2$, mild $-3-5$, moderate $-6-8$, and severe $-9-12$.

3. The impact of event scale (IES-R) - a 22-item questionnaire measures the symptomatic response to a traumatic event. It is scored on a 5 - point Likert scale ranging from 0 - no symptoms to 4 - maximum symptoms. There are three subscales (i.e., Intrusion, Avoidance, and Hyperarousal). The IES-R subscales have demonstrated high internal consistency, with Cronbach's alpha ranging from .79 to .91 , and test-retest reliability alpha ranging from 51 to 94.13 The mean IES-R score of 20 was taken as a positive screen for posttraumatic stress disorder as earlier studies have shown that the score of 20 and above measured by this scale, was correlated with diagnostic psychiatric interviews of PTSD. ${ }^{3}$

\section{Statistical Analysis}

The data so obtained was analysed using the Statistical Package for the Social Sciences 22.0 (IBM ${ }^{\circledR}$ SPSS ${ }^{\circledR}$ Statistics, New York, United States). The categorical values were described in percentages and frequency and continuous variables as mean and standard deviation. Chi-square test was performed to examine the relationship between categorical variables. Nonparametric test, the Kruskal-Wallis test, was applied where the continuous variable followed a non-normal distribution. Institutional Ethics Committee approval was obtained. 


\section{RESULTS}

\begin{tabular}{|cccc|}
\hline Variable & Categories & Frequency & Percentage \\
Gender & Male & 165 & 82.5 \\
& Female & 35 & 17.5 \\
& Illiterate & 14 & 7 \\
Education & Primary school & 33 & 16.5 \\
& High school & 60 & 30 \\
& Intermediate & 7 & 3.5 \\
Family type & Graduation and above & 86 & 43 \\
& Nuclear & 76 & 38 \\
Residence & Joint & 124 & 62 \\
& Urban & 126 & 63 \\
Marital status & Rural & 74 & 37 \\
& Married & 118 & 59 \\
& Unmarried & 65 & 32.5 \\
& Others & 17 & 8.5 \\
Occupation & Professional & 8 & 4. \\
& Semi professional & 25 & 12.5 \\
& Skilled & 30 & 15 \\
Family members & Semiskilled & 60 & 30 \\
effected & Unskilled & 41 & 20.5 \\
Deaths in the family & unemployed & 36 & 18 \\
& Not Effected & 32 & 16 \\
Variable & Effected & 168 & 84 \\
Age & No & 168 & 84 \\
Income & yes & 32 & 16 \\
Mays since discharge & Minimum & Maximum & Mean \\
Table 1. Sociodemographic Data of the Study Population \\
\hline
\end{tabular}

The results show that majority of the sample were males $(82.5 \%)$ with high school education (30\%) from an urban background (63\%) and married (59\%). Majority are employed in semiskilled occupation (30\%). The mean age of the population was 40 years, with an average income of 18,498 and were recruited in the study after an average of 40 days since discharge.

\begin{tabular}{|ccc|}
\hline Impact of Event Scale, Score & Frequency & Percent \\
Below 20 & 79 & 53.2 \\
Above 20 & 121 & 46.8 \\
\hline \multicolumn{3}{|c|}{ Table 2. Impact of Event Scale } \\
\hline
\end{tabular}

Table 2 shows $46.8 \%$ have scored above 20 , which is the number that indicates a positive screen for post traumatic disorder.

\begin{tabular}{|cccc|}
\hline Categories & Categories & Frequency & Percentage \\
& None $0-2$ & 96 & 48 \\
PHQ & Mild 3 - 5 & 68 & 34 \\
& Moderate 6-9 & 21 & 10.5 \\
& Severe > 9 & 15 & 7.5 \\
\hline \multicolumn{2}{|c|}{ Table 3. Patient Health Questionnaire Score (PHQ) } \\
\hline
\end{tabular}

Of the sample of $200,48 \%$ did not show any signs of psychological distress whereas $34 \%$ showed mild psychological distress.

\begin{tabular}{|c|c|c|c|c|}
\hline & Variable & IES $<20$ & IES $>20$ & P Value \\
\hline \multirow{5}{*}{ Education } & Illiterate & 4 & 10 & \multirow{5}{*}{0.005} \\
\hline & Primary & 15 & 18 & \\
\hline & High school & 32 & 28 & \\
\hline & Intermediate & 5 & 2 & \\
\hline & Graduation and above & 23 & 63 & \\
\hline \multirow{2}{*}{ Gender } & Male & 94 & 71 & \multirow{2}{*}{0.019} \\
\hline & Female & 8 & 33 & \\
\hline \multirow{3}{*}{ Marital status } & Married & 50 & 68 & \multirow{3}{*}{0.05} \\
\hline & Unmarried & 46 & 19 & \\
\hline & Others & 10 & 7 & \\
\hline \multirow{2}{*}{$\begin{array}{c}\text { Family member } \\
\text { effected }\end{array}$} & Yes & 73 & 95 & \multirow{2}{*}{.006} \\
\hline & No & 26 & 6 & \\
\hline \multirow{2}{*}{ Death in the family } & Yes & 44 & 88 & \multirow{2}{*}{0.01} \\
\hline & No & 35 & 33 & \\
\hline \multicolumn{5}{|c|}{$\begin{array}{l}\text { Table 4. Association between Sociodemographic } \\
\text { Features and the IES Scores }\end{array}$} \\
\hline
\end{tabular}

Association of various sociodemographic variables with IES scores was done using the chi-square test. The significant values are represented in table 5 . It was seen that in graduates and married people and in those where other family members were affected by the disease and deaths in the family due to Covid 19 , had scored significantly more on the IES scale.

\begin{tabular}{|ccccccc|}
\hline & Variable & $\begin{array}{c}\text { PHQ - No } \\
\text { Distress }\end{array}$ & $\begin{array}{c}\text { Mild } \\
\text { Distress }\end{array}$ & $\begin{array}{c}\text { Moderate } \\
\text { Distress }\end{array}$ & $\begin{array}{c}\text { Severe } \\
\text { Distress }\end{array}$ & $\begin{array}{c}\text { P } \\
\text { Value }\end{array}$ \\
Marital & Married & 54 & 41 & 14 & 9 & \\
status & Unmarried & 27 & 25 & 7 & 6 & .046 \\
& Others & 15 & 2 & 0 & 0 & \\
Residence & Urban & 70 & 32 & 11 & 13 & 0.001 \\
Family & Rural & 26 & 36 & 10 & 2 & \\
members & No & 26 & 2 & 1 & 3 & 0.00 \\
effected & Yes & 70 & 66 & 20 & 12 & \\
Deaths in & No & 69 & 38 & 1 & 5 & 0.00 \\
the family & Yes & 27 & 30 & 20 & 10 & \\
\hline \multicolumn{7}{c}{ Table 5. Association between Sociodemographic } \\
\end{tabular}

People who were married, belonging to rural area, having family members effected and having deaths in the family scored higher in the moderate to severe psychological distress. Correlation between the IES and PHQ scores was done using Spearman's correlation as the continuous scores followed a non-normal distribution and showed a strong positive correlation $(\mathrm{r}=.495, \mathrm{P}=0.00)$.

\section{DISCUSSION}

A total of 200 patients after one month of discharge were evaluated to understand the psychological symptoms. A total $46.8 \%$ scored significantly on the impact of event scale. However, the score only shows a positive screen for posttraumatic stress disorder and is not diagnostic in itself. A total of $10.5 \%$ and $7.5 \%$ scored moderate to severe on psychological distress respectively.

A study from China evaluating a similar population profile as our study of discharged patients infected with Covid 19 showed similar results with depression in $19 \%$ and anxiety in $12.4 \%$. As in our study, death in the family and number of family members effected was significantly associated with PTSD and anxiety. While death itself is a factor for distress in any person, having lost a loved one due to a sudden unexpected death because of Covid 19 may have contributed to the higher scores on the IES-R. Some of the other factors that contributed to anxiety, mentioned in the study from China which were not analysed in our study were the severity of the disease and perceived discrimination.

In the same study, higher education was an additional factor significantly associated with depression. ${ }^{14}$ In our study, though we did not focus on a diagnosis of depression, an education level of graduation and above showed significant association with psychological distress. One reason we hypothesise is that people with higher levels of education possibly spend more time seeking out information about the disease and those prone to anxiety would therefore show more signs of psychological distress. The browsing for information when the patient himself or his family members fall sick and receiving conflicting reports add up to the 
psychological distress and has indeed been one of the factors determined in a qualitative study done in Covid survivors. ${ }^{15}$

In another study done 3 months post discharge, female gender having prior mental illness were correlated strongly with having PTSD. ${ }^{16}$ Female gender was also significantly associated with symptoms of PTSD as measured by the IES-R in another study. ${ }^{17}$ This preponderance of the female gender has been shown in our study as well and the proposed mechanism maybe due to fluctuations in ovarian hormone levels which may account for the altered sensitivity to emotional stimuli during certain phases in the menstrual cycle. ${ }^{18}$ In addition, the multiple tasks a woman has to play in the household may account for increased psychological distress. A study from Israel showed significant distress in single people. ${ }^{19}$ Since majority of our study population lived in joint families, it may have acted as a social support and buffer against psychological distress. Our study found $46.5 \%$ to have scored above the cut off in IES-R. A study on the psychological distress in students and sanitary workers in a Spanish university also found similar value of $50.43 \%$ using the same scale during the current pandemic. ${ }^{20}$ The scores on the IES-R and the PHQ showed strong positive correlation, showing that the psychological symptoms in either form continue to persist even after one of recovery and discharge from the hospital.

\section{CONCLUSIONS}

As with other pandemics earlier, the Covid 19 pandemic has also left a mark on the mental health of the survivors. Targeted mental health support needs to continue long after physical recovery from the COVID 19 infection.

\section{Limitations and Strength of This Study}

The limitations of the study are that it is a single centre study, sampling was convenience sampling, and no control group was taken. These limitations need to be kept in mind while interpreting the results. The strength of this study is the use of structured scales and being the first one for such kind of study from India.

Data sharing statement provided by the authors is available with the full text of this article at jemds.com.

Financial or other competing interests: None.

Disclosure forms provided by the authors are available with the full text of this article at jemds.com.

\section{REFERENCES}

[1] Sahu KK, Mishra AK, Lal A, et al. India fights back: COVID19 pandemic. Heart Lung 2020;49(5):446-8.

[2] Hawryluck L, Gold WL, Robinson S, et al. SARS control and psychological effects of quarantine, Tornto, Canada. Emerg Infect Dis 2004;10(7):1206-12.

[3] Grover S, Dua D, Sahoo S, et al. Why all COVID-19 hospitals should have mental health professionals: the importance of mental health in a world crisis! Asian J Psychiatr 2020;51:102147.

[4] Cheng SKW, Wong CW, Tsang J, et al. Psychological distress and negative appraisals in survivors of severe acute respiratory syndrome (SARS). Psychol Med 2004;34(7):1187-95.

[5] Paules CI, Marston HD, Fauci AS. Coronavirus infectionsmore than just the common cold. JAMA 2020;323(8):707-8.

[6] Cai X, Hu X, Ekumi IO, et al. Psychological distress and its correlates among COVID-19 survivors during early convalescence cross age groups. Am J Geriatr Psychiatry 2020;28(10):1030-9.

[7] Gijzen M, Shields-Zeeman L, Kleinjan M, et al. The bittersweet effects of COVID-19 on mental health: results of an online survey among a sample of the dutch population five weeks after relaxation of lockdown restrictions. Int J Environ Res Public Health 2020;17(23):9073.

[8] Liang L, Gao T, Ren $\mathrm{T}$, et al. Post-traumatic stress disorder and psychological distress in Chinese youths following the COVID-19 emergency. Journal of Health Psychology 2020;25(9):1164-75.

[9] Liang X, Zhu Y, Fang Y. COVID-19 and post-traumatic stress disorder: a vicious circle involving immunosuppression. CNS Neurosci Ther 2020;26(8):876-8.

[10] Kroenke K, Spitzer RL, Williams JBW, et al. An ultra-brief screening scale for anxiety and depression: the PHQ-4. Psychosomatics 2009;50(6):613-21.

[11] Kroenke K, Spitzer RL, Williams JB. The PHQ-9:validity of a brief depression severity measure. J Gen Intern Med 2001;16(9):606-13.

[12] Spitzer RL, Kroenke K, Williams JB, et al. A brief measure for assessing generalized anxiety disorder: the GAD-7. Arch Intern Med 2006;166(10):1092-7.

[13] Weiss DS, Marmar CR. The Impact of Event ScaleRevised. In: Wilson JP, Keane TM, eds. Assessing psychological trauma and PTSD. New York: Guilford Press 1997:399-411.

[14] Liu D, Baumeister RF, Veilleux JC, et al. Risk factors associated with mental illness in hospital discharged patients infected with COVID-19 in Wuhan, China. Psychiatry Res 2020;292:113297.

[15] Moradi Y, Mollazadeh F, Karimi P, et al. Psychological disturbances of survivors throughout COVID-19 crisis: a qualitative study. BMC Psychiatry 2020;20:594.

[16] Tarsitani L, Vassalini P, Koukopoulos A, et al. Posttraumatic stress disorder among COVID-19 survivors at 3-month follow-up after hospital discharge. J Gen Intern Med 2021;36(6):1702-7.

[17] Liu N, Zhang F, Wei C, et al. Prevalence and predictors of PTSS during COVID-19 outbreak in China hardest-hit areas: Gender differences matter. Psychiatry Res 2020;287:112921.

[18] Soni M, Curran VH, Kamboj SK. Identification of a narrow post-ovulatory window of vulnerability to distressing involuntary memories in healthy women. Neurobiol Learn Mem 2013;104:32-8.

[19] Lahav Y. Psychological distress related to COVID-19-the contribution of continuous traumatic stress. J Affect Disord 2020;277:129-37.

[20] Odriozola-González P, Planchuelo-Gómez Á, Irurtia MJ, et al. Psychological effects of the COVID-19 outbreak and lockdown among students and workers of a Spanish university. Psychiatry Res 2020;290:113108. 